\title{
A comprehensive review of synchronization methods for grid-connected converters of renewable energy source
}

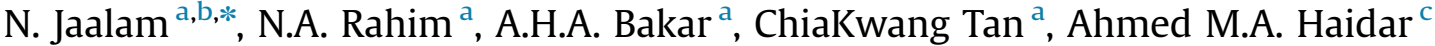 \\ ${ }^{a}$ UM Power Energy Dedicated Advanced Centre (UMPEDAC), University of Malaya, Malaysia \\ ${ }^{\mathrm{b}}$ Faculty of Electrical E' Electronics Engineering, Universiti Malaysia Pahang, Malaysia \\ ${ }^{\mathrm{c}}$ Department of Electrical and Electronic Engineering, Universiti Malaysia Sarawak, Malaysia
}

\section{A R T I C L E I N F O}

Article history:

Received 28 October 2014

Received in revised form

16 August 2015

Accepted 13 January 2016

Available online 4 February 2016

Keywords:

Grid synchronization

Grid-connected converter

Phase angle estimation

Frequency estimation

Phase-locked loop

\begin{abstract}
A B S T R A C T
Recent interest in the integration of renewable energy sources (RES) into the power grid has raised concerns in synchronization of the various RES. Grid variables such as voltage, phase angle and frequency should be continuously monitored to guarantee correct operation and synchronization of power converters connected to the power grid. Numerous synchronization methods have been presented over the years to address issues such as unbalanced condition and frequency variation. This paper presents a review of past studies on synchronization methods for grid-connected converters together with their control and modeling techniques. Various estimation techniques for phase angle, frequency and harmonic are discussed and examined. Key challenges for a smart and efficient synchronization are briefly overviewed and possible future works are also recommended. A consolidated review is the particular focus of this paper, as is the provision of information on the best method for synchronizing grid-connected converters.
\end{abstract}

c) 2016 Elsevier Ltd. All rights reserved.

\section{Contents}

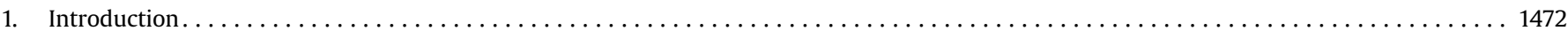

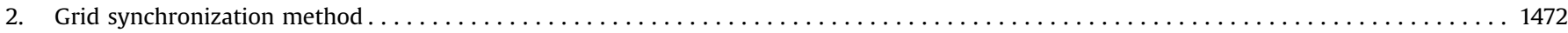

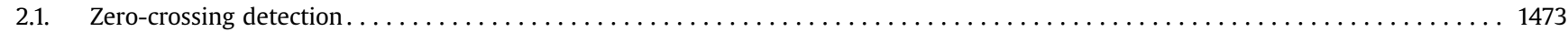

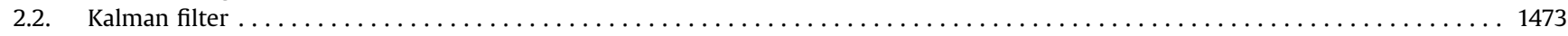

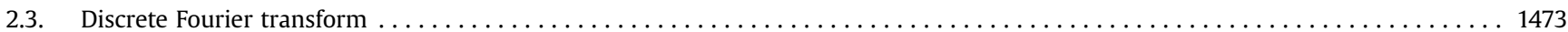

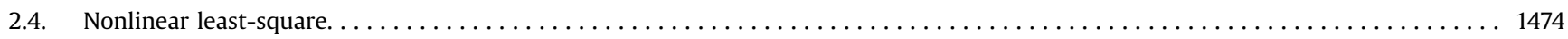

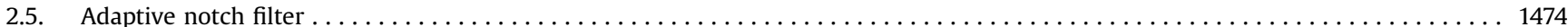

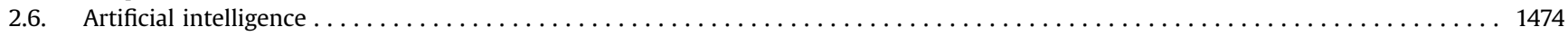

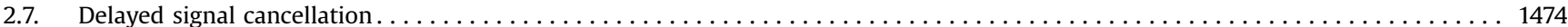

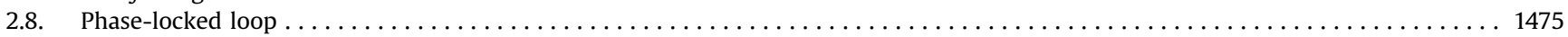

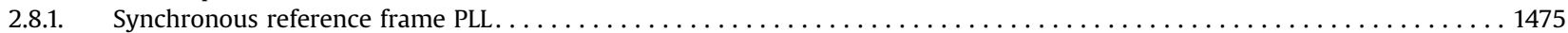

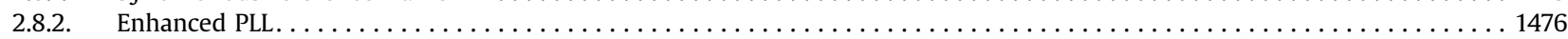

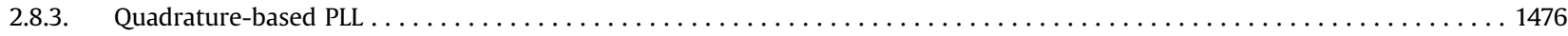

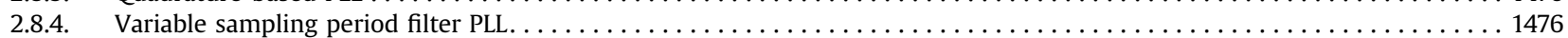

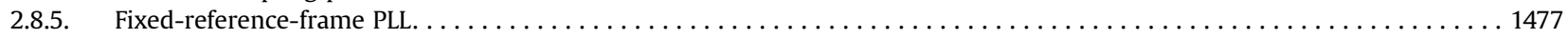

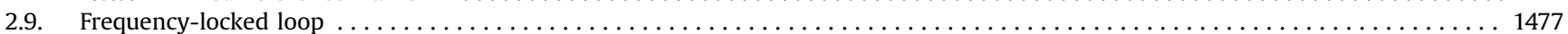

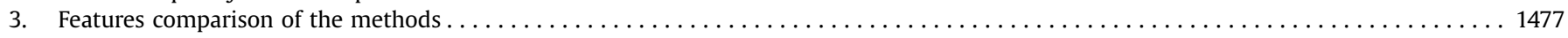

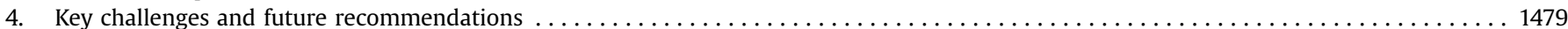

\footnotetext{
* Corresponding author. Tel.: +60 322463246.

E-mail address: zila@ump.edu.my (N. Jaalam).
} 


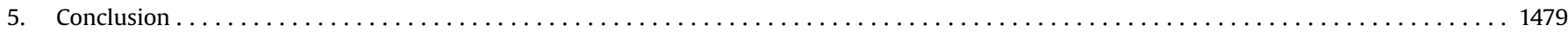

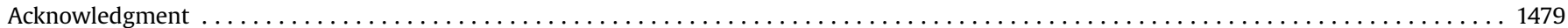

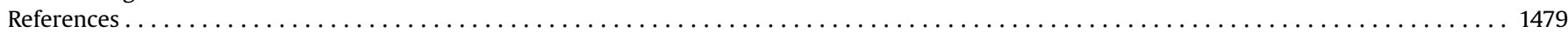

\section{Introduction}

Distributed generation (DG) systems based on RES such as wind, solar, and hydro are now popular options to reducing the world's dependence on fossil-based fuels, which are known to deplete sooner or later [1,2]. As reported in [3], 80\% of energy generation in this world depends on fossil fuels, which contribute to global warming. Consumption of fossil fuels is estimated to increase by $1.5 \%$ annually until 2030 , with $2.2 \% \mathrm{CO}_{2}$ emission [4]. Therefore, the use of RES must be prioritized because up until today only $15-20 \%$ of energy are from RES even though they are abundant $[4,5]$. However, many issues and technical challenges remain to be considered for successful integration of RES into the utility grid. One of the most important issue is synchronization of the grid-side converter, where output voltage waveform has to be synchronized with the grid voltage to secure continuous and stable operation [6-10]. The situation becomes more critical when the utility grid is subjected to disturbances and unbalanced faults [11]. During such faults, the grid-side converters are exposed to three severe problems: excessive DC link voltage, high AC current, and loss of grid voltage synchronization [12].

Synchronization can be defined as the minimization of the variances in voltage, phase angle, and frequency between the RES generator output and the grid supply $[13,14]$. Such synchronization must be achieved before connecting the RES generator into the power grid $[13,14]$. It allows the grid and the synchronized power converter to work together [15]. According to [16], an ideal synchronization approach must:

- Competently track the phase angle of the utility grid.

- Efficiently detect the frequency variations.

- Efficiently eliminate disturbances and high harmonic components.

- Immediately respond to utility grid changes.

The standards of power quality cannot otherwise be achieved. With high penetration of RES into grid, the different small generators connected to the grid cause power quality problems, as does the unpredictable and time-varying nature of RES (especially wind and solar) $[17,18]$. Correspondingly, the unbalanced relationship between demand and supply might cause nominal frequency deviation in that system. If the total generation exceeds demand due to the surplus internal power exported to the grid by the RES, the frequency will be increased and vice versa. This frequency deviation may destroy the mechanical system of the rotating machines and cause other related problems that can jeopardize the stability of the power system [19]. Hence, to avoid control difficulties and power outages, the power grid frequency should stay within its permissible limits [20]. Several grid codes (e.g., IEEE Std. 1547, IEEE Std. 1588-2008, IEC Std. 1727, IEEE Std. 929-2000) that indicate the limits for frequency, voltage, harmo- nics, and power rating have been introduced to address this issue [21]. Frequency tracking and estimation are therefore crucial for synchronizing and protecting the power grid and maintaining its power quality and reliability [22,23]. Other than the grid variables stated above, the detection of possible harmonic components produced by the power converter is gaining more attention nowadays as harmonic components can cause control errors and increase loss in equipment [24-28].

Table 1 lists a variety of grid-connected devices that need to be accurately synchronized with the grid voltage and Fig. 1 illustrates the application of grid synchronization in grid-connected power converter control.

Given the multitude of problems concerning grid synchronization, various estimation methods for phase angle, frequency, and harmonic estimation have been proposed for synchronization of grid-connected converters. Published reviews of synchronization methods exist but the behavior and methodologies have not been discussed in detail. This study will bridge that research gap. Its main objective is to provide a comprehensive review of the existing synchronization methods plus their advantages and shortcomings. Detailed analyses on the application of these methods are presented and their dynamic response is quantified. The findings of this paper should help researchers identify the best technique for their product or application. The paper's organization is as follows: Section 2 presents the various synchronization methods so far proposed for grid integration; Section 3 presents comparisons and analyses of the methods; Section 4 overviews the key challenges to smart synchronization methods and recommends possible future work; and Section 5 concludes the review.

\section{Grid synchronization method}

Rapid proliferation of DG in power grid has given rise to the proposal of numerous synchronization methods such as zero crossing detection (ZCD) [31-34], Kalman Filter [35,36], discrete Fourier transform (DFT) [37,38], nonlinear least square (NLS) [39], adaptive notch filtering (ANF) [40-45], artificial intelligence (AI) $[46,47]$, delayed signal cancellation (DSC) [48-53], phase locked loop (PLL) [54-78], and frequency locked loop (FLL) [30,79-82]. These methods can be classified as frequency domain or time domain. In this paper, however, the classification is by application, for either single-phase system or three-phase system. Further classification narrows these down into open-loop and closed-loop systems, as seen in Fig. 2. Open-loop systems directly detect the magnitude, phase, and frequency of the input signal, whereas closed-loop systems adaptively update the detected parameters through a loop mechanism. Over the years, three-phase systems are more popular than single-phase systems because in singlephase systems the tasks of grid fundamental and harmonic

Table 1

Grid-connected devices that need to be synchronized with the grid voltage [29].

\begin{tabular}{|c|c|}
\hline Group of devices & Applications \\
\hline Renewable Energy Source (RES) & Photovoltaic power plants, wind power plants, nuclear power plants, etc. \\
\hline Flexible AC Transmission Systems (FACTS) & Static Var Compensator (SVC), Static Compensator (STATCOM), Static Series Synchronous Compensator (SSSC), etc. \\
\hline Custom Power Systems (CUPS) & Active Power Filter (APF), Uninterruptible Power Supply (UPS), Dynamic Voltage Restorer (DVR), D-STATCOM, etc. \\
\hline Loads & AC loads with AC/DC converters, DC loads cooperating with grid-connected converters (AC/DC) \\
\hline
\end{tabular}

